\title{
Influence of Eastern Mediterranean Gas Discoveries on European Energy Security
}

\author{
Elnur T. Mekhdiev \\ Financial University under the Government of the Russian \\ Federation \\ Moscow, Russia
}

\author{
Alexander S. Vereshchagin, Guzel F. Kadyrova, \\ Nail F. Gindullin \\ Ufa State Petroleum Technological University \\ Ufa, Russia
}

\author{
Sharbatullo D. Sodikov \\ Moscow State Institute of International Relations (University) of the Ministry of Foreign Affairs of the Russian Federation \\ Moscow, Russia
}

\begin{abstract}
The article introduces recent developments in energy sector in the Eastern Mediterranean. Over the past decade, Israel, Cyprus, and Egypt turned from energy importers into exporters. Now each of them possess abundant natural gas deposits and strives to profit from exports. With two major players as the EU and Turkey, the issue becomes politicized. The main driver for European gas policy is the diversification of its suppliers while Turkey is on the way to become natural gas hub between Europe and Middle East. The authors examine natural gas deposits and possibilities to export in Israeli and Cypriot. There are three options as Eastern Mediterranean, IsraeliTurkish pipeline and Egyptian LNG fields. And the authors prioritize the latter as the most profitable.
\end{abstract}

Keywords-Natural gas; EU; East-Med pipeline project

\section{INTRODUCTION}

Recent developments on European energy markets show that the cornerstone of European energy policy is the securitization of energy flows. Dependence on Russian gas once lead to energy shortages during winters of 2006 and 2009. Now European bureaucracy pursues to reach independence through several ways and most important of those seems to be the diversification of the sources where European consumers get their energy from [2].

Majority of the world's leading think-tanks and energy companies agree upon the fact that natural gas is going to firm its share in the European energy consumption. According to experts, the consumption of natural gas in Europe will remain stable at the current level. The average annual indicator in the long term by various sources amounts to $450 \mathrm{bcma}$. The European Commission with 429 bcma provides the minimum figure. The International Energy Agency assumes a consumption level of 466 bcma, and Eurogas figures 437 - 585 bcma [7]. Unlike consumption, domestic gas production will decline significantly. According to the International Energy Agency in 2040, it will be 91 bcma, which is $47 \%$ less than the level of 2013 . Thus, the EU will import $83 \%$ of the gas consumed. In the long term, the minimum level of imports in total gas consumption is $68 \%$ according to ENTSO-G, and BP believes that imports will be $75 \%$.
Discovery of several natural gas fields in the Eastern Mediterranean made some experts to assume that those discoveries will alter the energy politics of the EU and adjacent regions significantly. Still some experts opined that the proved and probable volumes of the discovered fields are not enough to change the geopolitics of the region. The certain is the following - now Israel possesses enough natural gas to be net exporter of the fossil fuels and Cyprus' case is close to Israeli one if several problems are resolved.

\section{METHODOLOGY}

Within scope of this study authors apply the system approach of social sciences. The system approach does not exist in the form of a rigorous methodological concept - it performs its heuristic functions, remaining not very tightly bound by a set of cognitive principles, the main meaning of which is the appropriate orientation of specific studies.

In the system study, the analyzed object is considered as a certain set of elements, the interrelation among which determines the integral properties of the set. The main emphasis is put on identifying the variety of relationships and relationships that take place both within the object under study and in its relationships with the external environment and the environment. The properties of an object as an integral system are determined not only and not so much by the summation of the properties of its individual elements, as by the properties of its structure, by special system-forming, integrative links of the object under consideration. Particular importance in the system approach is attached to the identification of the probabilistic nature of the behavior of the objects under study. An important feature of the system approach is that not only the object, but also the research process itself acts as a complex system, the task of which, in particular, consists in uniting various models of the object. 


\section{OVERVIEW OF RECENT NATURAL GAS DISCOVERIES IN THE ISRAELI AND CYPRIOT EEZS}

In the recent decade, there were several significant gas discoveries in the Eastern Mediterranean.

Leviathan is the largest gas field in the EEZ of Israel. It was discovered in 2010. Confirmed reserves add up to 476 bcm. The gas fields is developed by Noble Energy $39.66 \%$, operator), Delek Group with $43.33 \%$ and Ratio with $15 \%$. According to the development plan, the first volumes of gas from this field should enter the market by the end of 2019. The planned volume of gas production in the first phase is $21 \mathrm{bcma}$ [1].

At the beginning of the development of the field, the population of Haifa actively opposed to this project because the deposit is located in close proximity to the city. Nevertheless, Bini Zomer, Vice President of Noble Energy for regional issues, said that the development of the deposit occurs at a depth of $5 \mathrm{~km}$ and at a distance of $100 \mathrm{~km}$ from the shore and taking into account all threats to the environment poses no danger.

There is a problem with the sale of products, since no sufficient number of buyers have been found so that the development of the field will pay off. So far, only one major contract has been concluded with the Jordanian state-owned electric power company NEPCO. The total sales volume should reach $45 \mathrm{bcm}$ within 15-17 years without possibility of reduction of purchases. The remaining 4 contracts are concluded with Israeli companies, the total supply volume is $31 \mathrm{bn} \mathrm{m} 3$ for $15-20$ years with the possibility of reducing the volume of purchases. Thus, Leviathan faced the problem of exporting gas to international markets. In 2015, an agreement was concluded for the export of gas to Egypt, both for domestic consumption and for potential supplies to LNG fields. But the discovery of the Zohr field in 2015 put the implementation of this agreement to question.

The Tamar field was discovered in 2009, gas production began in early 2013. The volume of overall gas in the estimated reserves is 282 bn $\mathrm{m} 3$. Development consortium of the field consists of Noble Energy (operator) - 32.5\%, Delek Drilling - 31.2\%, Isramco - 28.7\%, Dor Gas - 4\%, and Everest - $3.5 \%$ [1]. According to the law adopted by the Israeli government, that halts monopolies and regulates companies in the gas industry (Government Gas Framework), Delek Group should sell its stake in Tamar field before the end of 2021, and Nobel Energy should reduce its share to $25 \%$. The annual production level is about $11.5 \mathrm{bcma}$.

According to the law of $2015,40 \%$ of produced gas can be exported, and $60 \%$ must remain for domestic consumption. The two largest purchasers of gas in the Israeli market are Israel Electric Corporation $(87 \mathrm{bcm})$, Or Power Energies (Dalia) Ltd (23 bcm). Private manufacturing companies contracted $58 \mathrm{bcm}, 6$ billion cubic meters were allocated to Oil Refineries Ltd. $3.3 \mathrm{bcm}$ were contracted by other companies. A contract was signed with the Egyptian Dolphinus Holdings for 7 years, but the fulfillment of the contract depends on transport routes. Negotiations are underway with the Spanish Union Fenosa for gas supplies to the LNG fields in Damietta in Egypt, it is planned to supply $4.5 \mathrm{bcm}$ annually for 15 years, with a possible increase in supplies of up to $7 \mathrm{bcm}$.

Tanin and Karish were discovered in 2011 and 2013 respectively. It is developed for domestic Israeli consumption as the export quota was transferred to the consortium Leviathan during the sale of the field in 2016. The developer is Energean Israel Ltd., a subsidiary of the Greek company Energean, which acquired in August 2016 the development rights from Noble Energy and Delek Group after the adoption of the Government Gas Framework in 2015. Contracts have already been signed for the purchase of gas from these fields with the private Israeli electricity company Or Power Energies (Dalia) Ltd. The volume of the contracted gas is $23 \mathrm{bcm}$. According to the representative of the company, gas will be sold at a lower price than the gas purchased by Israel Electric Corp. It is expected that gas supplies will begin in 2021.

Aphrodite is a gas field in the Cyprus EEZ. The field was discovered by Delek Group and Noble Energy in 2011. The volume of gas amounts to $140 \mathrm{bcm}$. Noble Energy (35\%, operator), Delek Group (30\%) and Shell (35\%) develop the field [1]. This gas field has several problems. Firstly, the lack of domestic demand for natural gas. The majority of power stations in Cyprus operate on oil. Now the authorities of Cyprus are facing the issue of transferring power plants to gas consumption. Even in the case of gasification, the size of the country's economy is still small for commercial development and the produced gas needs to be exported. Secondly, there is a lack of export gas pipelines. One option is the East-Med gas pipeline, which could potentially link Israeli deposits to Italy via Cyprus and Greece. The second option is the construction of a gas pipeline from Aphrodite to LNG fields in Egypt, but this option depends on the volume of gas production in Egypt itself and its export opportunities. Third, some researchers put forward the idea that the amount of Cyprus' reserves is not enough for their commercial development due to the lack of gas infrastructure on the island. Favorable is the option of joint development of Aphrodite and Israeli Leviathan fields, the distance between them is only $7 \mathrm{~km}$. In addition, in terms of export by some researchers, a joint sale of the products of the triangle Zohr (Egypt) - Leviathan (Israel) - Aphrodite (Cyprus) is beneficial. Fourthly, the problem is the position of Turkey in relation to the issuance of licenses by the government of South Cyprus.

\section{EXPORT POSSIBILITIES FOR EASTERN MEDITERRANEAN NATURAL GAS}

Currently three major regional players influence the development of the natural gas resources of the East Mediterranean. They are the EU, Turkey and Egypt. Each of them has their own plans on how to develop the regional energy cooperation and own vision of the future interaction in the region. Most active among them is Turkey with its set vision for the region and goals to achieve. The EU with its strive for independence in dealing with energy issues has basic instruments and mechanisms when it comes to deal with new potentially lucrative gas fields. Egypt is the most passive due to domestic issues and security problems. Still it affects the East Mediterranean energy interaction by possessing vast 
amounts of gas and thus becoming a competitor for Israel and Cyprus in a certain way.

The most important issue on the agenda from the point of view of solving the problems that remain in the region is how the energy resources will be transported. While looking at the projects that stand out in the region, the East Mediterranean Pipeline project, initiated by Israel, Greece and the Greek authorities of South Cyprus, bypassing the territory of Turkey, comes to the forefront.

The pipeline with the length of more than $1,300 \mathrm{~km}$ will start in Israel and will have three exit points: Cyprus, Crete and Greece, and further - to Italian terminals [5]. The project should pay off in ten years, based on the average annual throughput of 1.34 bcf without any additional investment. Greek DEPA and Italian Edison (a gas operator under the wing of the French giant Électricité de France with assets of over 70 billion euros) now divide financial responsibility equally.

Participation of large European capital makes its own peculiarities in the interpretation of the goals and meanings of the project, including political ones. From the very beginning, EastMed's project was presented to the media as an instrument of the EU strategy to reduce European energy dependence from Moscow in the face of escalating conflict and mutual sanctions. However, none of the countries participating in EastMed has confirmed the anti-Russian nature of the project. Gas from Russia remains the optimal solution for Europe.

However, given the route of this project, obviously, it is not the most financially lucrative. Moreover, this project actually remains on the agenda with the help of the EU. But the problem of financing and the limited amount of reserves in the region are the most important obstacles that stand in the way of implementing this route [8].

This is due to the fact that the amount of investment and the costs required for the planned project increase the price of gas in the Eastern Mediterranean. Therefore, EU countries that want both competition and the opportunity to buy cheaper gas are turning to alternative routes.

The Turkish route to transport East-Mediterranean natural gas is the shortest ( $\sim 550 \mathrm{~km})$. Owing to this, Israel will be able to quickly deliver its gas to Europe. However, Israel may not want to get into transit dependence on Turkey, although the two countries signed an agreement on the normalization of relations at the end of June 2016. Israel now shows Turkey that it has an alternative and can supply its gas to Europe via the future EastMed gas pipeline. Israel is interested in, firstly, to start gas supplies to Turkey, which is a major buyer of gas, and, secondly, to start gas supplies to Europe. The cheapest and the shortest way to deliver Israeli (Eastern Mediterranean) gas to Europe is through a pipeline through the Mediterranean to Turkey (Mersin province), and in this case, there will most likely not be a need to build a second, longer and more expensive EastMed gas pipeline. However, the second pipeline is certainly needed for Israel in terms of diversifying gas exports. It seems that if Israel acts together with Cyprus and Greece, a long and expensive gas pipeline may be built, but if Israel acts alone, the construction of the Israel-Turkey gas pipeline from which Israeli gas will enter Europe is be more likely. Turkey stands for the construction of the pipeline. In this case, Turkey will increase the number of gas suppliers, and it will be able to reduce its dependence on the three major ones (Russia, Iran and Azerbaijan). This mainly concerns Russia and Iran, since the price of gas from these countries far exceeds the price of Azerbaijani gas. Currently, the TransAnatolian gas pipeline (TANAP) is under construction along which, Azerbaijani gas will be delivered to Turkey and, further, to Europe with Trans-Adriatic (TAP) gas pipeline. Azerbaijan will become the second major gas supplier of Turkey. Theoretically, gas from Turkmenistan, Iran, Iraq and Qatar can also be delivered to Europe via this gas pipeline. In addition, Russian gas can be supplied to Europe via the Turkish Stream gas pipeline. Now Turkey must fight for the delivery of Eastern Mediterranean gas to Europe through its territories. If the gas of all the above-mentioned countries is transported to Europe via Turkey, it will probably become the largest gas corridor in the world, as gas of about 10 countries will be sent to Europe via one country.

The biggest problem for the transportation of the natural gas from the Levantine basin through Turkey is European diversification policy. With the construction of the pipeline from Israel to Turkey coupled with the Southern Gas Coridor, the EU seems to become dependent on Turkey after Russia. The Southern Gas Corridor is a project initiated by the European Commission aimed at diversifying both supplying countries and routes for the transport of natural gas to Europe. The Southern Gas Corridor project was proposed after the abolition of the Nabucco transport project. The starting point of the route is the Sangachal terminal near Baku, and the final point is in Italy. The gas pipeline itself consists of three parts: the South Caucasus, Trans-Anatolian (TANAP) and TransAdriatic (TAP) gas pipelines.

The first part of the Southern Gas Corridor is the South Caucasus Gas Pipeline (also called the Baku-Tbilisi-Erzurum gas pipeline). This route exports Azerbaijani gas from the Shah Deniz field. Deliveries to Georgia via the gas pipeline began in late 2006, and to Turkey in July 2007. The throughput capacity is $8 \mathrm{bcma}$. The gas pipeline is laid in close proximity to the Baku-Tbilisi-Ceyhan oil pipeline in order to minimize damage to the ecological environment of the region. The shares of companies in the consortium are distributed as follows: BP (operator) - 28.8\%, SOCAR (through AzSCP) $10.0 \%$, TPAO - 19\%, Petronas - 15.5\%, Lukoil - 10\%, NICO $10 \%$ and SGC Midstream - 6.7\% [4].

By 2020, it is planned to increase capacity to 20 billion $\mathrm{m} 3$ per year by installing two additional compressor stations on the territory of Georgia and Turkey and the construction of a second line parallel to the already existing pipeline. The final decision on investments in the Expanded South Caucasus Gas Pipeline was signed on December 17, 2013, simultaneously with the decision to develop the second phase of the Shah Deniz field.

The second part of the Southern Gas Corridor is the TransAnatolian Gas Pipeline (TANAP). The idea of the project was proposed at the III Black Sea Energy and Economic Forum, held in Istanbul in November 2011. The Memorandum of 
Understanding on the construction of a gas pipeline between the governments of Azerbaijan and Turkey was signed in December 2011. The construction of the 1850-kilometer pipeline began in March 2015. Initial design capacity of the gas pipeline is $16 \mathrm{bcma}$, of which ten are intended for the European market, and six for the Turkish market. By 2026, it is planned to increase the volume of transported gas to 31 bcma. The share of companies in the project is as follows $58 \%$ is owned by Azerbaijan's SOCAR through Southern Gas Corridor Closed Joint Stock Company, Turkish BOTAS owns $30 \%$, and BP holds $12 \%$ [6].

The third line of the Southern Gas Corridor is the TransAdriatic Gas Pipeline (TAP). In 2013, a tripartite intergovernmental agreement was signed between Greece, Italy and Albania, confirming the commitment to the project. The share participation of companies in this project is distributed as follows: BP - 20\%, SOCAR - 20\%, Snam S.p.A. - 20\%, Fluxys - 19\%, Enagás - 16\% and Axpo - 5\% [3].

It is worth noting the activities of the governments of the Balkan countries to support the Trans-Adriatic gas pipeline. Memorandums of understanding and cooperation were signed between the governments and the companies-developers of the countries participating in the TAP projects and the IonianAdriatic Pipeline (IAP). On May 27, 2013, the Council of the Adriatic and Ionian Initiative, represented by the heads of governments of Albania, Bosnia and Herzegovina, Croatia, Greece, Italy, Montenegro, Serbia and Slovenia, signed in Brussels a declaration of consent for cooperation on the further development of the TAP and IAP gas pipelines. The main beneficiaries of the transit of Caspian gas through the Southern Gas Corridor are the countries of South-Eastern Europe, for whom this project is one of the most important variables in the process of diversifying natural gas suppliers to national markets.

It is worth noting the interest of Bulgaria in the construction of TAP with its aim to become natural gas hub of the Eastern Europe. In January 2014, a Memorandum of Understanding and Cooperation was signed between TAP operators and the Greece-Bulgaria Interconnector (IGB).

In the long term, Turkmenistan appears to be a potential supplier of natural gas to fill the Southern Gas Corridor. The country has a huge amount of natural gas, and transportation makes it easy for the fact that the offshore fields are only 100 kilometers from Azerbaijan. After the discovery of the Galkanysh deposit, the world's largest gas field onshore, the volume of Turkmenistan's confirmed gas reserves reached $17.5 \mathrm{tcm}$. The level of production as for today is about 70 bcma, of which 40 are exported. The only importer of Turkmen gas currently is China.

Azerbaijan has clearly expressed its position regarding the transportation of natural gas from Turkmenistan to Europe and appears to be a reliable partner. Azerbaijan is ready to act as a transit point for Turkmen and Kazakh gas to Turkey and Europe.

The most profitable option to transport natural gas from the Levantine Basin to Europe is to deliver fuel for LNG fields in Egypt. Currently, there are two in the country - in Idku and
Damietta. However, there are also problems. Several years ago Egypt needed gas and its domestic production was not enough even to cover its own needs, but the discovery of the Zohr field turned this situation upside down. The volume of proved reserves of the fiedls is $850 \mathrm{bcm}$. This allows Egypt to both develop its own consumption and export fuel. Nevertheless, many experts have suggested that it is more profitable for the three countries to unite their efforts and jointly solve the problem of exporting natural gas.

\section{CONCLUSION}

As the consumption of natural gas in Europe increases against the reduction in its production, it is important for European countries to diversify natural gas supplies. The discovery of the new fields in the east of the Mediterranean Sea off the coast of Israel, Cyprus and Egypt opened up new opportunities for the EU. At the same time, there is a problem with the definition of supply routes.

The EastMed pipeline project supported by the EU Commission is the most expensive and least profitable from an economic point of view. It is also difficult to perform from a technical point of view, as it passes through the seismically active zones of the Mediterranean Sea, and the depth at several sites is more than 3000 meters. The possibility of repairing damaged areas at such a depth is not entirely obvious.

The project of the pipeline from Israel to Turkey with the subsequent export of gas to Europe is technically possible and economically profitable. Nevertheless, there are several problems. First, this pipeline passes through the Syrian EEZ. Secondly, the EU also does not want Turkey to become a gas hub. Otherwise, Turkey will control the transportation of large quantities of natural gas imported by Europe.

It seems that the export of natural gas from Cyprus and Israel to Egypt, followed by liquefaction and export to various parts of the world with the help of a tanker is the most advantageous option for these countries.

\section{REFERENCES}

[1] East Med E\&P: Our Business Environment, 2018. Retrieved from: https://www.delek-group.com/our-operations/east-med-our-businessenvironment/

[2] M. Hafner and S. Tagliapietra, The Role of Natural Gas in EU Decarbonisation Path. Fondazione Eni Mattei Milano, 2016.

[3] Shah Deniz Stage Two, Caspian Sea, 2018. Retrieved from: https://www.offshore-technology.com/projects/shah-deniz-stage-2caspian-sea/

[4] BP, South Caucasus pipeline, 2018. Retrieved from: https://www.bp.com/en_az/caspian/operationsprojects/pipelines/SCP.ht $\mathrm{ml}$

[5] S. Tagliapietra, Energy Relations in the Euro-Mediterranean. Palgrave Macmillan, 2017.

[6] Trans Anatolian Natural Gas Pipeline Project, 2018. Retrieved from: http://www.tanap.com

[7] International Energy Agency, World Energy Outlook 2017. Executive Summary. $\quad$ Retrieved from: https://www.iea.org/publications/freepublications/publication/WEO_201 7_Executive_Summary_English_version.pdf

[8] V. Yorucu and O. Mehmet, The Southern Energy Corridor: Turkey's Role in European Energy Security. Springer International Publishing, 2018. 